Running head: SUBJECTIVE PREFERENCES

Toddlers and preschoolers understand that some preferences are more subjective than others

Tiffany Doan, Ori Friedman, and Stephanie Denison

Department of Psychology, University of Waterloo

Corresponding author: Tiffany Doan (t3doan@uwaterloo.ca)

200 University Ave W, Waterloo, Ontario, N2L 3G1; 519-888-4567

This paper is not the copy of record and may not exactly replicate the final, authoritative version of the article. Please do not copy or cite without author's permission. 


\begin{abstract}
Four experiments examined Canadian 2-3-year-old children's ( $N=224 ; 104$ girls, 120 boys) thoughts about shared preferences. Children saw sets of items, and identified theirs and another person's preferences. Children expected that food preferences would be more likely to be shared than color preferences, regardless of whether the items were similar or different in appeal (Experiments 1-3). A final study replicated these findings while also exploring children's expectations about activity and animal preferences. Across all studies, children expected shared preferences at surprisingly low rates (never higher than chance). Overall, these findings suggest that young children understand that some preferences are more subjective than others, and that these expectations are driven by beliefs about domains of preferences.
\end{abstract}

Keywords: preferences, theory of mind, subjectivity, social cognition 


\section{Toddlers and preschoolers understand that some preferences are more subjective than}

others

All preferences are subjective, but some preferences are more subjective than others. Suppose you like cookies more than celery, and the color blue more than red. You might anticipate that many people will share your preference for cookies over celery, but fewer will share your preference for blue over red. These expectations could depend on the strength of your preferences. Your preference for cookies might be much stronger than your preference for blue. Alternatively, these expectations could depend on domain. Perhaps, preferences for foods are generally more likely to be shared than preferences for colors. Either way, these expectations demonstrate that you view the subjectivity of preferences as relative and have a sense of which preferences are likely to be shared by others.

In this paper, we explore young children's understanding of the subjectivity of preferences. Expectations about which preferences are likely to be shared could allow children to infer preferences when little information is available. Young children might assume by default that a complete stranger will probably share their preference for Oreos, but hold off from assuming the stranger shares their regard for the color blue. Also, understanding children's expectations about which preferences are likely to be shared could inform us about how they conceive of preferences more generally.

We know that young children understand that their preferences are subjective and not always shared by others. For example, 18-month-olds appear to understand their preference for Goldfish crackers over broccoli is not shared by an adult who reacts negatively to the Goldfish and positively to the broccoli (Repacholi \& Gopnik, 1997; but see Ruffman et al., 2018 for a review of failed replications). Two-year-olds consider preferences that differ from their own 
when predicting others' actions (Wellman \& Woolley, 1990), and spontaneously mention contrasts between their preferences and those of others (Wellman \& Bartsch, 1994). Children's recognition of shared versus differing preferences impacts their social behavior. For instance, infants and preschoolers prefer playing with peers who share their preferences (Fawcett \& Markson, 2010b; Mahajan \& Wynn, 2012), prefer items endorsed by those who have previously shared their preferences (Fawcett \& Markson, 2010a), and avoid items endorsed by those who have opposed their preferences (Lumeng et al., 2008).

We do not know, though, whether children understand that some preferences are more likely to be shared than others. In most studies on judgments about preferences, children have information about other people (e.g., emotional reactions, repeated choices) that allow their preferences to be inferred. But investigating expectations about whether preferences are shared requires withholding this information and instead manipulating the items the preferences concern. Previous work shows that young children do anticipate variations in whether facts are likely to be known (e.g.., Cimpian \& Scott, 2012; also see Baer \& Friedman, 2016; Gelman et al., 2013). But no work has examined if children have similar expectations about preferences. If children do have expectations about which preferences are likely to be shared, what might underlie these expectations? One possibility is that they use the strength of their own preferences to infer those of others, expecting strong preferences to be shared and weaker preferences to not be shared. People do something similar when attributing knowledge: They may assume others will know facts that come easily to their own minds (Birch et al., 2017). So with preferences, children might attribute the strength of their feelings to others.

Alternatively, children could have an intuitive framework from which they generate expectations about the kinds of items or domains that are likely to have shared preferences. For 
example, they might expect their preferences for foods to be shared, but assume that other people will not share their color preferences. The domain of food may be especially likely to involve shared preferences. Innate, biological processes may make some foods more universally preferred than others (Ventura \& Mennella, 2011). Further, care needs to be taken in food selection to avoid ingesting toxins and poisons (Rozin, 1976), so there is good reason to share the same food preferences as others. Eating is a social phenomenon and food preferences can be influenced by others (e.g., Birch, 1980; Frazier et al., 2012; Shutts et al., 2009; Shutts et al., 2013), so very young children might expect others to share food preferences more than other preferences. Consistent with this idea, 14-month-olds consider social relationships between people to generalize food preferences, but not for object preferences (Liberman et al., 2016). We explored these issues in four experiments on children aged 2 and 3. Because we were interested in children's initial beliefs about shared preferences, and because we used a verbal task, we began our investigation at age 2 . In each experiment, children were shown pairs of items and were asked which item they preferred, and which was preferred by another person. Our main interest was whether matching responses for self and other would be more common for some pairs than others, and whether variations across pairs might depend on the strength of the preferences or on item domain. We examine the strength account by assessing consistency (whether individual children in our experiments choose the same item in a pair consistently) and consensus (how likely an item is to be chosen across all children in a given comparison). As a first step, children in Experiment 1 were asked about the foods and colors from our opening example (i.e., cookies vs celery; red vs blue). Experiments 2 and 3 then explored children's judgments about other foods and colors. Finally, Experiment 4 also investigated the domains of activities and animals. 


\section{Experiment 1}

\section{Methods}

Participants. We tested 32 2-year-olds $(M=2 ; 9$ [years; months]; range $=2 ; 3-2 ; 11 ; 18$ girls) between October 2018 and February 2019. Two additional children were tested and excluded; one did not provide any responses and the other did not provide responses when asked what the experimenter liked. Children from all experiments were individually tested at daycares and schools in a mid-sized Canadian city in Southwestern Ontario. Demographic information was not formally collected, but the region is predominantly middle-class, and approximately $81 \%$ of residents in this region are White, with Chinese and South Asians as the most visible minorities (Statistics Canada, 2017). This research, submitted under the name, "Social Understanding in Children" (ORE\#30395), received ethics clearance through the University of Waterloo's Research Ethics Board.

Materials and procedure. In each of four trials, children were shown pictures on a laptop of four items (see Figure 1) and were first asked about which item they liked (e.g., "Which food do you like?"), and then about which item the experimenter liked (e.g., "Which food do I like?"). In two food trials, they chose between Oreos and celery. In two color trials, they chose between red and blue rectangles. In administering the task, the items were not labelled or described (e.g., the experimenter did not say "cookies" or "Oreos").

Each trial included two pictures of each item (e.g., two pictures of Oreos) so that children could attribute the same preference to themselves and the experimenter without pointing to the same picture twice. We included two trials of each type (e.g., two food trials) to assess the consistency of children's choices. The four trials alternated between food and color trials, with half the children seeing food trials first. For the second trial of each type, half the children saw 
the items in the exact same location as the first trial of that type, and the other half saw them in a different location.

\section{Results and Discussion}

Data for all experiments are available at https://osf.io/4y $3 \mathrm{k} 2 /$. In each experiment, generalized estimating equation models (binary logistic; unstructured correlation matrices) examined whether children indicated that they and the experimenter had the same preference or not. In each model, age in months was mean-centred and entered as a covariate. Domain was entered as a factor, along with any other predictors, and we tested for all possible interactions. Table 1 lists the factors entered into each model and all effects. All analyses reported here are confirmatory; although we did not pre-register the analyses, we used the same approach as in other recent papers (e.g., Doan et al., in press; Nancekivell et al., 2020; Thorburn et al., 2020).

Children were more likely to predict shared preferences for foods than for colors, Wald $X^{2}(1)=12.15, p<.001$; see Figure 1 . There was also a significant interaction between domain and age, Wald $X^{2}(1)=5.71, p=.017$. However, when separately examining each domain, we found no significant effects of age, $p s \geq .519$. As Figure 1 shows, children did not expect shared preferences at high rates in either condition, and this was also true in the other experiments; we address this pattern in the General Discussion. 
Table 1

Factors and Effects from each Analysis

\begin{tabular}{|c|c|c|c|c|c|}
\hline Experiment & Factors & Effects & Wald $X^{2}$ & $d f$ & $p$ \\
\hline \multirow[t]{3}{*}{1} & domain: color, food & domain & 12.15 & 1 & $<.001$ \\
\hline & age in months & age & 0.27 & 1 & .606 \\
\hline & & domain*age & 5.71 & 1 & .017 \\
\hline \multirow[t]{3}{*}{2} & domain: color, food & domain & 7.70 & 1 & .006 \\
\hline & age in months & age & 0.21 & 1 & .648 \\
\hline & & domain*age & 2.92 & 1 & .088 \\
\hline \multirow[t]{7}{*}{3} & domain: color, food & domain & 7.36 & 1 & .007 \\
\hline & $\begin{array}{l}\text { question-order: child first, } \\
\text { Morgan first }\end{array}$ & question-order & 0.35 & 1 & .554 \\
\hline & age in months & age & 1.99 & 1 & .158 \\
\hline & & domain*question-order & 1.59 & 1 & .208 \\
\hline & & domain*age & 0.12 & 1 & .729 \\
\hline & & question-order*age & 0.46 & 1 & .499 \\
\hline & & $\begin{array}{l}\text { domain*question- } \\
\text { order*age }\end{array}$ & 0.23 & 1 & .630 \\
\hline \multirow[t]{7}{*}{4} & $\begin{array}{l}\text { domain: color, food, } \\
\text { activity, animal }\end{array}$ & domain & 9.37 & 3 & .025 \\
\hline & set-type: Set 1 , Set 2 & set-type & 2.15 & 1 & .142 \\
\hline & age in months & age & 2.54 & 1 & .111 \\
\hline & & domain*set-type & 3.21 & 3 & .360 \\
\hline & & domain*age & 3.14 & 3 & .370 \\
\hline & & set-type*age & 0.18 & 1 & .669 \\
\hline & & domain*set-type*age & 4.72 & 3 & .193 \\
\hline
\end{tabular}

We used two measures to assess whether one item in each pair was more strongly preferred than the other. First, Cohen's $\kappa$ assessed children's internal consistency—whether they attributed the same preference to themselves across the first and second trial of each trial type (e.g., whether they indicated the same food preferences in both food trials). Children were moderately consistent with their color preferences, $\kappa=.552, p=.001$, and only fairly consistent with their food preferences, $\kappa=.385, p=.006$ (these strength benchmarks are from Landis $\&$ Koch, 1977). Second, tests against chance assessed whether children were overall more likely to 
pick one item from each pair than the other (see Supplemental Materials for percentages of children's preferred items for all experiments). These tests showed that children preferred Oreos over celery, $p<.001$, whereas their color preferences did not differ from chance, $p=.162$.

In sum, children judged that shared preferences were more likely for the foods than for the colors. This finding could result from toddlers viewing food preferences as less subjective than color preferences. But this conclusion is premature because we only looked at one pair of foods and one pair of colors. Also, this difference could have arisen because children's relative preference for Oreos over celery may have been stronger than their relative preference between the colors. So the results might differ if children were asked about similarly appealing foods, but about colors where one is much more attractive than the other.

We addressed this possibility in Experiment 2. We used foods anticipated to be similarly appealing, Oreos and chocolate chip cookies. We also chose colors that differed in attractiveness, bright blue and opaque couché, which has been deemed the world's ugliest color and has been used on cigarette packaging to deter smoking (e.g., Wells, 2012). We also expanded the age range to include 3-year-olds, to examine whether there are developmental changes in children's preference predictions. 

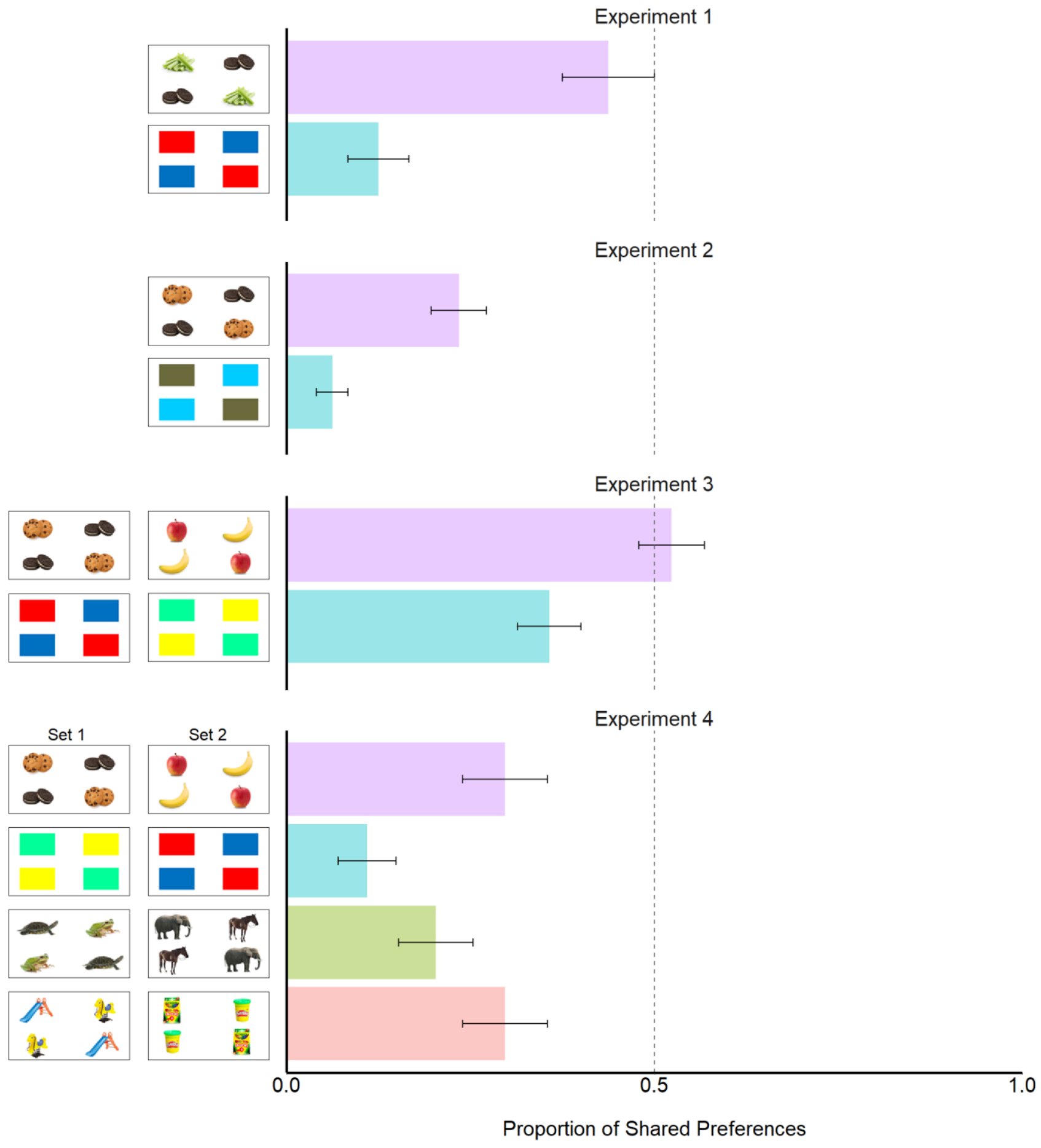

\section{Experiment 2}

Figure 1. Children's proportion of shared preferences for all experiments. Error bars show \pm 1 standard error of the mean. 


\section{Experiment 2}

\section{Methods}

Participants. We tested $642-3$-year-olds $(M=3 ; 0 ;$ range $=2 ; 0-3 ; 11 ; 26$ girls $)$ between February 2019 and May 2019. One additional child was tested and excluded because they did not provide any responses.

Materials and procedure. We used the procedure from Experiment 1, but with new stimuli (see Figure 1). In the food trials, children chose between Oreos and chocolate chip cookies. In the color trials, they chose between bright blue and a shade of greenish-brown, sometimes characterized as the world's ugliest color (Pantone 448C).

\section{Results and Discussion}

Children again were more likely to predict shared preferences for foods than colors, Wald $X^{2}(1)=7.70, p=.006$; see Figure 1 . No other effects were significant, $p \mathrm{~s} \geq .088$.

Children's color preferences were fairly consistent, $\kappa=.387, p=.001$, but their food preferences were not, $\kappa=.171, p=.156$. Tests against chance indicated that most children preferred bright blue over greenish-brown, $p<.001$. Unexpectedly, most children also preferred Oreos over chocolate chip cookies, $p=.050$.

These findings suggest that young children's expectations depend on domain rather than on the relative strengths of preferences. If children's expectations had been based on relative strengths, they should have been more likely to expect shared preferences for colors than foods. Instead, they showed the reverse pattern.

The next experiments further investigated whether children's expectations of shared preference depend on domain. To this end, we tested whether the findings extend to other colors 
and foods. These experiments used pairs of items anticipated to be similarly appealing, as we sought to manipulate domain without manipulating the relative strength of preferences.

The next experiment also introduced other procedural changes. In both experiments so far (but especially Experiment 2), attributions of shared preferences were relatively rare. One contributing factor might have been that children assumed that an adult's preferences would differ from their own. Hence, the next experiments examined children's judgments about a gender-matched child. Also, because we were concerned that continuously alternating between asking about self and other would be confusing, trials were blocked. Children were asked about their preferences in one block, and about the other child's in another block (block order was counterbalanced across children).

\section{Experiment 3}

\section{Methods}

Participants. We tested 64 2-3-year-olds $(M=2 ; 11 ;$ range $=2 ; 0-3 ; 11 ; 29$ girls $)$ between May 2019 and November 2019. One additional child was tested and excluded because they did not provide responses for the food trials.

Materials and procedure. Children were first shown a picture of a gender- and agematched child named Morgan. They were told that they would be asked about what they like and about what Morgan likes. Children again participated in two food trials and two color trials (see Figure 1 for sample stimuli). In food trials, children chose between Oreos and chocolate chip cookies, and between an apple and a banana. In color trials, children chose between red and blue, and between green and yellow. Half the children were first asked about their preferences (e.g., “Which food do you like?") on all four trials, then were asked about Morgan's (e.g., "Which 
food does Morgan like?"). On trials where children were asked about Morgan's preferences, an image of Morgan appeared in the centre of the screen, between all the items.

\section{Results and Discussion}

Question-order (child first, Morgan first) was added as a factor in the model. Children were more likely to predict shared preferences between themselves and Morgan for foods than for colors, Wald $X^{2}(1)=7.36, p=.007$; see Figure 1. No other effects reached significance, all $p \mathrm{~s}$ $\geq .158$.

Tests against chance indicated that children did not significantly prefer one color over the other, $p \mathrm{~s} \geq .529$. Children also did not have a systematic preference between apples and bananas, $p=.454$, but they did prefer Oreos over chocolate chip cookies, $p=.003$.

These findings again suggest that children think food preferences are more shared than color preferences. In the final experiment, we again asked children about foods and colors, but also asked about two other domains. Including further domains allows us to determine whether children have distinct expectations about each domain, or whether they instead view one domain as unique. For instance, they might think food preferences are generally more shared than preferences from numerous other domains, or that color preferences are generally more subjective than preferences from other domains. In this last experiment, we also randomly assigned children to see either of two sets of stimuli (i.e., so that each domain was not just investigated with one pair of items). 


\section{Experiment 4}

\section{Methods}

Participants. We tested 64 2-3-year-olds $(M=3 ; 0$; range $=2 ; 1-3 ; 11 ; 31$ girls $)$ between November 2019 and February 2020. One additional child was tested and excluded because they only answered what they liked and not what Morgan likes.

Materials and procedure. As in Experiment 3, children were introduced to a picture of Morgan, and were told that they would be asked about what they like and about what Morgan likes. Children again participated in four trials, but one from each of four domains: foods, colors, activities, and animals. Half the children saw one set of stimuli, and the other half saw a different set of stimuli; see Figure 1 for a sample of the stimuli. Because question-order had no effect in Experiment 3, children were first asked about their own preferences, and then about Morgan's.

\section{Results and Discussion}

Set-type $(1,2)$ was added as a factor in the model. Children's shared preferences between themselves and Morgan depended on the domain, Wald $X^{2}(3)=9.37, p=.025$; see Figure 1 . No other effects reached significance, all $p \mathrm{~s} \geq .111$. Children were more likely to predict shared preferences for foods than for colors, $p=.014$, and for activities than for colors, $p=.011$. There were no differences in children's predictions of shared preferences between foods and activities, $p>.999$, foods and animals, $p=.180$, colors and animals, $p=.134$, and activities and animals, $p$ $=.157$.

For Set 1 , tests against chance indicated that children did not significantly prefer one item over the other in any domain, $p_{\text {foods }}=.724, p_{\text {colors }}=.292, p_{\text {activities }}=.162, p_{\text {animals }}=.292$. For Set 2 , children did not prefer one item over the other for three domains, $p_{\text {foods }}=.724, p_{\text {colors }}=.724$, and $p_{\text {animals }}=.082$, but did prefer playdoh over crayons, $p_{\text {activities }}=.017$. 
In sum, children were again more likely to expect shared preferences for foods than for colors. Also, children's expectations about sharing of activity preferences were similar to those for food, with greater expectation of shared activity than color preferences. Findings for animal preferences were non-conclusive because expectations for this domain did not significantly differ from expectations about any other domain. Importantly, the findings were robust to changes in items, as there were no differences between our two sets of stimuli.

\section{General Discussion}

Across four experiments, children aged 2-3 were more likely to judge that another person would share their preferences between foods than their preferences between colors. This pattern was consistent across several sets of items, and regardless of whether children anticipated the experimenter's preferences or those of another child. Our final experiment also showed that children's expectations about shared preferences between activities were similar to their expectations concerning foods, and this experiment yielded indeterminate findings for shared preferences for animals.

Together these findings show that toddlers and young preschoolers recognize that some preferences are more likely to be shared than others. Earlier work had demonstrated that young children understand that preferences are subjective (e.g., Repacholi \& Gopnik, 1997) and that children can use a variety of cues to infer preferences, including information about people's choices and emotional reactions, and information about the surrounding context (e.g., JaraEttinger et al., 2016; Kushnir et al., 2010; Ma \& Xu, 2011). The present work is novel in showing that even without seeing another person choose items or respond to them, children have expectations about which of their preferences are shared with that person. 
Our findings also suggest that children's expectations about shared preferences are organized by domain. Most notably, children expect preferences between foods to be shared more than preferences between colors. We initially contrasted the possibility of organization by domain with the possibility that children would infer shared preferences based on relative strength. Specifically, we thought it plausible that if children strongly prefer one item over another, they might assume that others would likewise share this preference, which could be a useful heuristic for inferring shared preferences. However, the findings speak against this account. For example, greater expectations of shared preferences for foods than colors were found even when choices were between similarly appealing foods but differently-attractive colors. Further, children who were internally consistent (i.e., chose the same item on repeated trials and thus an arguably strong preference), showed the same overall pattern of expecting more shared preferences for food than color sets (see Supplemental Materials for this comparison).

It should be acknowledged that in two out of three experiments, children unexpectedly preferred Oreos to chocolate chip cookies. Though this is not ideal, the potential difference in strength of preference for these items does not undermine the main finding: They were chosen at similar rates as the preferred item for children in Experiment 4; Oreos were much less strongly preferred than was blue over greenish-brown in Experiment 2; and the other food stimuli (apples and bananas) were equally preferred by children and produced similar effects. In all of these cases the domain difference persisted. We should also acknowledge a potential concern with our measure of strength. We gauged strength by assessing consistency of preferences within individual children and by assessing consensus across children. But these are not direct measures 
of strength. For example, consistently preferring blue over red does not necessarily imply that blue is strongly preferred over red.

One avenue for further testing the domain- and strength-based accounts might be to ask children about others' preferences (for studies examining such inferences, see Diesendruck \& haLevi, 2006; Graham et al., 2006; Heyman \& Gelman, 2000) for items which are novel and unfamiliar. For example, children could be told that a certain individual prefers green berries over purple ones, and prefers one novel musical instrument over another. Domain-based judgments should lead children to conclude that other people will be more likely to share the food preferences than the musical instrument preference. A strength-based account should not predict this, however, as children would have no basis from which to judge the strength of each preference.

One notable aspect of our findings is that children did not generally expect their preferences to be shared, and never anticipated shared preferences at above-chance rates (see Figure 1). So, though children were more likely to expect shared preferences for food than colors, they did not strongly anticipate that food preferences were shared. This notably diverges from how young children attribute epistemic mental states. Children often struggle to acknowledge that others do not share their beliefs (e.g., Wellman et al., 2001) and privileged knowledge (e.g., Birch \& Bloom, 2003).

However, the structure of our tasks may have contributed to this pattern of different responses for self and other. For example, children might have felt compelled to switch responses across trials. One reason to suspect that our task promoted switching is that both infants (e.g., Mahajan \& Wynn, 2012) and 5-year-olds (DeJesus et al., 2019) appear to dislike others who do not share their food preferences. Therefore, it is surprising that children predict 
such a high proportion of unshared preferences, unless they also assume they will dislike nearly everyone they meet! Importantly, though, the possibility of inflated predictions of non-shared preferences does not undermine the main conclusion that expectations of shared preferences are more common for some domains (e.g., foods) than others (e.g., colors).

One question raised by our experiments is whether similar findings would also be observed in older children. While a definitive answer will require further research, we see reason to expect both continuity and change with age. Like our participants, older children (and adults) might also expect shared preferences to be more likely in some domains than others. But we suspect that with age, judgments might also come to depend on preference strength. For example, although older children might retain the expectation that color preferences are often idiosyncratic, they might nonetheless recognize that most people will share their preference for bright blue over opaque couché.

Returning to early development, we close with a somewhat ironic speculation relating to Repacholi and Gopnik's (1997) seminal investigation. They investigated whether 18-month-olds recognize that their preferences between foods are not shared by an adult whose reactions to foods are opposite to those of the children themselves. Although we cannot be sure that the conclusions from our studies extend to children under age two, our findings suggest that the domain of foods might be comparatively challenging for exploring the subjectivity of preferences. Our findings raise the possibility that young children might need less evidence to recognize that their color preferences are not shared. Indeed, they might expect this by default and experience more difficulty recognizing that these can be shared. 
Generalizability. In all experiments, we tested participants from a Western, educated, industrialized, rich, and democratic (WEIRD; Henrich et al., 2010) society. As such, we must not assume that our results would generalize to non-WEIRD populations. 


\section{References}

Baer, C., \& Friedman, O. (2016). Children's generic interpretation of pretense. Journal of Experimental Child Psychology, 150, 99-111. doi: 10.1016/j.jecp.2016.05.004

Birch, L. L. (1980). Effects of peer models' food choices and eating behaviors on preschoolers' food preferences. Child Development, 489-496. doi: 10.2307/1129283

Birch, S. A., \& Bloom, P. (2003). Children are cursed: An asymmetric bias in mental-state attribution. Psychological Science, 14, 283-286. doi: 10.1111/1467-9280.03436

Birch, S. A., Brosseau-Liard, P. E., Haddock, T., \& Ghrear, S. E. (2017). A 'curse of knowledge' in the absence of knowledge? People misattribute fluency when judging how common knowledge is among their peers. Cognition, 166, 447-458. doi:

10.1016/j.cognition.2017.04.015

Cimpian, A., \& Scott, R. M. (2012). Children expect generic knowledge to be widely shared. Cognition, 123, 419-433. doi: 10.1016/j.cognition.2012.02.003

Diesendruck, G., \& haLevi, H. (2006). The role of language, appearance, and culture in children's social category-based induction. Child Development, 77, 539-553. doi: $10.1111 / \mathrm{j} .1467-8624.2006 .00889 . \mathrm{x}$

Diesendruck, G., Salzer, S., Kushnir, T., \& Xu, F. (2015). When choices are not personal: The effect of statistical and social cues on children's inferences about the scope of preferences. Journal of Cognition and Development, 16, 370-380. doi: $10.1080 / 15248372.2013 .848870$

Doan, T., Friedman, O., \& Denison, S. (in press). Oh...so close! Children's close counterfactual reasoning and emotion inferences. Developmental Psychology. 
Fawcett, C. A., \& Markson, L. (2010a). Children reason about shared preferences. Developmental Psychology, 46, 299-309. doi: 10.1037/a0018539

Fawcett, C. A., \& Markson, L. (2010b). Similarity predicts liking in 3-year-old children. Journal of Experimental Child Psychology, 105, 345-358. doi: 10.1016/j.jecp.2009.12.002

Frazier, B. N., Gelman, S. A., Kaciroti, N., Russell, J. W., \& Lumeng, J. C. (2012). I'll have what she's having: The impact of model characteristics on children's food choices. Developmental Science, 15, 87-98. doi: 10.1111/j.1467-7687.2011.01106.x

Graham, S. A., Stock, H., \& Henderson, A. M. (2006). Nineteen-month-olds' understanding of the conventionality of object labels versus desires. Infancy, 9, 341-350. doi: 10.1207/s15327078in0903_5

Gelman, S. A., Ware, E. A., Manczak, E. M., \& Graham, S. A. (2013). Children's sensitivity to the knowledge expressed in pedagogical and nonpedagogical contexts. Developmental Psychology, 49, 491-504. doi: 10.1037/a0027901

Jara-Ettinger, J., Gweon, H., Schulz, L. E., \& Tenenbaum, J. B. (2016). The naïve utility calculus: Computational principles underlying commonsense psychology. Trends in Cognitive Sciences, 20, 589-604. doi: 10.1016/j.tics.2016.05.011

Henrich, J., Heine, S. J., \& Norenzayan, A. (2010). The weirdest people in the world? Behavioral and Brain Sciences, 33, 61-83. doi: 10.1017/S0140525X0999152X

Heyman, G. D., \& Gelman, S. A. (2000). Preschool children's use of trait labels to make inductive inferences. Journal of Experimental Child Psychology, 77, 1-19. doi: 10.1006/jecp.1999.2555 
Kushnir, T., Xu, F., \& Wellman, H. M. (2010). Young children use statistical sampling to infer the preferences of other people. Psychological Science, 21, 1134-1140. doi: $10.1177 / 0956797610376652$

Landis, J. R., \& Koch, G. G. (1977). The measurement of observer agreement for categorical data. Biometrics, (33), 159-174. doi: 10.2307/2529310

Liberman, Z., Woodward, A. L., Sullivan, K. R., \& Kinzler, K. D. (2016). Early emerging system for reasoning about the social nature of food. Proceedings of the National Academy of Sciences, 113, 9480-9485. doi: 10.1073/pnas.1605456113

Lumeng, J. C., Cardinal, T. M., Jankowski, M., Kaciroti, N., \& Gelman, S. A. (2008). Children's use of adult testimony to guide food selection. Appetite, 51, 302-310. doi:

10.1016/j.appet.2008.03.010

Ma, L., \& Xu, F. (2011). Young children's use of statistical sampling evidence to infer the subjectivity of preferences. Cognition, 120, 403-411. doi: 10.1016/j.cognition.2011.02.003

Mahajan, N., \& Wynn, K. (2012). Origins of "us" versus "them": Prelinguistic infants prefer similar others. Cognition, 124, 227-233. doi: 10.1016/j.cognition.2012.05.003

Nancekivell, S. E., Ho, V., \& Denison, S. (2020). Who knows what? Preschoolers appreciate the link between ownership and knowledge. Developmental Psychology, 56, 880-887. doi: $10.1037 / \operatorname{dev} 0000918$

Repacholi, B. M., \& Gopnik, A. (1997). Early reasoning about desires: evidence from 14-and 18month-olds. Developmental Psychology, 33, 12-21. doi: 10.1037/0012-1649.33.1.12

Rozin, P. (1976). The selection of foods by rats, humans, and other animals. York: Academic Press. doi: 10.1016/S0065-3454(08)60081-9 
Ruffman, T., Aitken, J., Wilson, A., Puri, A., \& Taumoepeau, M. (2018). A re-examination of the broccoli task: Implications for children's understanding of subjective desire. Cognitive Development, 46, 79-85. doi: 10.1016/j.cogdev.2017.08.001

Shutts, K., Kinzler, K. D., \& DeJesus, J. M. (2013). Understanding infants' and children's social learning about foods: Previous research and new prospects. Developmental Psychology, 49, 419-425. doi: 10.1037/a0027551

Shutts, K., Kinzler, K. D., McKee, C. B., \& Spelke, E. S. (2009). Social information guides infants' selection of foods. Journal of Cognition and Development, 10, 1-17. doi: $10.1080 / 15248370902966636$

Statistics Canada. 2017. Kitchener - Cambridge - Waterloo [Census metropolitan area], Ontario and Ontario [Province] (table). Census Profile. 2016 Census. Statistics Canada Catalogue no. 98-316-X2016001. Ottawa. Released November 29, 2017. https://www12.statcan.gc.ca/census-recensement/2016/dp-pd/prof/index.cfm?Lang=E (accessed July 3, 2020).

Thorburn, R., Bowman-Smith, C. K., \& Friedman, O. (2020). Likely stories: Young children favor typical over atypical story events. Cognitive Development, 56, 100950. doi: 10.1016/j.cogdev.2020.100950

Ventura, A. K., \& Mennella, J. A. (2011). Innate and learned preferences for sweet taste during childhood. Current Opinion in Clinical Nutrition \& Metabolic Care, 14, 379-384. doi: 10.1097/MCO.0b013e328346df65

Wellman, H. M., \& Bartsch, K. (1994). Before belief: Children's early psychological theory. In C. Lewis \& P. Mitchel (Eds.) Children's early understanding of mind: Origins and development. (pp. 331-354). Psychology Press. 
Wellman, H. M., Cross, D., \& Watson, J. (2001). Meta-analysis of theory-of-mind development: The truth about false belief. Child Development, 72, 655-684. doi: 10.1111/14678624.00304

Wellman, H. M., \& Woolley, J. D. (1990). From simple desires to ordinary beliefs: The early development of everyday psychology. Cognition, 35, 245-275. doi: 10.1016/00100277(90)90024-E

Wells, R. (2012, August 17). Does this colour turn you off? Retrieved July 01, 2020, from https://www.brisbanetimes.com.au/national/does-this-colour-turn-you-off-2012081624bf4.html 